\title{
PERCEPÇÃO E CONFORTO DOS USUÁRIOS DO PARQUE TRIANON EM SÃO PAULO/SP
}

PERCEPTION AND COMFORT OF USERS OF THE TRIANON PARK IN SÃO PAULO CITY

\author{
LÉa YAMAguch Dobbert \\ Arquiteta, doutora em Recursos Florestais pela Escola Superior de Agricultura "Luiz de Queiroz" da \\ Universidade de São Paulo, Piracicaba - SP. \\ leadobbert@gmail.com
}

Alessandra Rodrigues Prata-Shimomura

Arquiteta, Professora doutora do Depto. de Tecnologia da arquitetura - FAU/USP arprata.shimo@gmail.com

Helena Cristina Padovani Zanlorenzi

Arquiteta, doutoranda pela Faculdade de Arquitetura e Urbanismo - FAU/USP helenapadovani@gmail.com

Maria de Assunção Ribeiro Franco

Professora Titular do Depto. de Projetos - FAU/USP

mariafranco@usp.br

\begin{abstract}
RESUMO
O excesso de impermeabilização do solo e a crescente verticalização, unidos ao adensamento dos grandes centros metropolitanos, têm prejudicado as condições térmicas do espaço urbano. A presença de vegetação em parque urbanos pode atenuar esses efeitos na medida em que proporciona maior conforto aos seus usuários. $O$ presente estudo analisou a percepção e conforto dos usuários do parque Tenente Siqueira Campos (Trianon) na cidade de São Paulo. A quantidade de cobertura arbórea na área de estudo, assim como em seu entorno, foi calculada pelo método de classificação supervisionada. Para a avaliação das condições térmicas foram aferidas as seguintes variáveis climáticas: temperatura e umidade relativa do ar, temperatura de globo e a velocidade do vento, a fim de verificar as condições do microclima local. Questionários, contendo questões relacionadas ao conforto e à sensação térmica foram aplicados aos usuários para detectar o grau de satisfação em relação ao parque. Constatou-se, pelo relato dos entrevistados, que estes demonstraram satisfação
\end{abstract}


e bem estar no local analisado. As variáveis climáticas aferidas mostraram condições de microclima agradável com temperatura (máx. $29^{\circ} \mathrm{C}$ e mín. $22,80^{\circ} \mathrm{C}$ ) e umidade relativa (máx. 69\% e mín. 49\%) contribuindo assim para o conforto de seus usuários. Evidenciou-se a interferência da presença de vegetação na sensação de bem estar da população entrevistada comprovando a influência positiva das árvores inseridas no meio urbano.

Palavras-chave: Conforto térmico; Ambiente urbano; Microclima; Parque Trianon; Classificação supervisionada

\begin{abstract}
The excess of soil sealing and the growing verticalization, together with the densification of the great metropolitan centers, have been affecting the thermal conditions of the urban environment. The presence of vegetation in urban parks may mitigate these effects as it provides more comfort to its users. The present study analyzes the perception and comfort of the users of the Tenente Siqueira Campos Park (Trianon) in São Paulo City. The quantity of arboreal covering in the study area, as well as in its surroundings, was calculated by the supervised classification method. For the thermal conditions evaluation, the following climatic variables were considered: temperature and relative air humidity, globe temperature and the speed of the wind, aiming to verify the conditions of the local microclimate. Questionnaires containing queries related to comfort and thermal sensation were applied to the users aiming to detect the degree of satisfaction in relation to the park. It was observed through the interviewees' reports, that they showed satisfaction and well-being at the analyzed site. The measured climatic variables showed pleasant microclimate conditions with temperature ( $\max .29^{\circ} \mathrm{C}$ and $\min .22,80^{\circ} \mathrm{C}$ ) and relative air humidity (max. $69 \%$ and $\min .49 \%)$, thus contributing to the comfort of the users. It was highlighted the interference of the presence of vegetation in the sense of well-being of the interviewed population, testifying the positive impact of the trees inserted in the urban environment.
\end{abstract}

Keywords: Thermal Comfort; Urban Environment; Microclimate; Trianon Park; Supervised Classification 


\section{INTRODUÇÃO}

A remoção de cobertura vegetal e sua substituição por várias estruturas edificadas causam alterações no microclima urbano provocando desconforto térmico aos seus habitantes. $O$ excesso de pavimentação do solo e a crescente verticalização, unidos ao adensamento dos grandes centros metropolitanos, têm prejudicado as condições térmicas do espaço urbano, refletindo diretamente no conforto térmico humano. Um dos impactos observados por estas mudanças na estrutura das cidades é o aumento da temperatura de superfície e consequente alteração do microclima urbano.

Este tipo de impacto pode ser minimizado por meio de identificação de problemas e implementação de sistemas adequados de planejamento urbano com soluções que visem melhorar as condições de conforto nas cidades (OLIVEIRA e MASCARÓ, 2008, SENANAYAKE et al., 2013). Neste sentido, Norton et al. (2015) destacam a importância de se implementar estratégias para melhorar a infraestrutura verde das cidades com o intuito de atenuar a temperatura de superfície e consequentemente melhorar as condições climáticas dos locais onde a temperatura do ar e a radiação solar apresentam-se elevadas.

A vegetação, ao amenizar a temperatura do ar, contribui de forma significativa para o bem estar dos usuários do espaço urbano ao mitigar os efeitos negativos das ilhas de calor (DIMOUNDI e NIKOLOPOULOU, 2003; SPANGENBERG et al., 2008) contribuindo também na redução da temperatura radiante média, uma das variáveis climáticas que mais afetam as condições de conforto térmico humano (KÁNTOR E UNGER, 2011, COHEN et al., 2012).

A inserção de diferentes arranjos de cobertura arbórea tem se mostrado eficiente nas alterações microclimáticas conforme pesquisa realizada na Grécia por Shashua-Bar et al. (2010). Pesquisas demonstram efeitos positivos da arborização no microclima urbano ao contribuir para redução da temperatura e aumento da umidade relativa do ar (DOBBERT et al., 2014; SHASHUA-BAR et al., 2011). Além disso, as árvores contribuem também para o escoamento superficial e reduzem a poluição do ar (MC PHERSON et al., 2011). A influência positiva da vegetação sobre o microclima das cidades, bem como o conforto térmico de espaços abertos, podem ser evidenciados em estudos realizados por Dacanal e Labaki (2010); Cheng et al. (2009), entre outros.

No ambiente urbano a satisfação térmica dos cidadãos é importante para a promoção da saúde e bem estar de sua população. O contato com o ambiente natural é conside- 
rado por muitos pesquisadores como peça chave para aumentar o bem-estar, aliviar o estresse e promover melhor qualidade de vida às pessoas (KAPLAN, 1995, ULRICH 2002, HARTIG, 2014).

Cenas da natureza são em geral preferidas pelo homem por conterem elementos que proporcionam tranquilidade e calma (KAPLAN e KAPLAN,1983, ULRICH, 1981). Deste modo, áreas verdes por interferirem de forma positiva nas condições climáticas do meio ambiente urbano, proporcionam maior conforto térmico promovendo o bemestar aos seus usuários.

O presente estudo tem como objetivo avaliar a percepção e conforto dos usuários do parque Tenente Siqueira Campos (Trianon) na cidade de São Paulo, um dos parques contidos no Projeto de Pesquisa FAPESP N²015/10597-0, coordenado pela Prof ${ }^{a}$ Dra Maria de Assunção Ribeiro Franco, do qual sou pesquisadora associada.

\section{MATERIAIS E MÉTODOS}

\section{1 ÁREA DE ESTUDO}

São Paulo está localizada no estado de São Paulo, latitude 2332'52" S, longitude 46³8'09" W e altitude média de $760 \mathrm{~m}$. O clima é o tipo Cwa segundo classificação de Köppen-Geiger, com verão quente e chuvoso e inverno seco e ameno, precipitação média anual de $1441 \mathrm{~mm}$. Segundo as Normais Climatológicas (1961-1990) do INMET (Instituto Nacional de Meteorologia), as temperaturas máximas variam entre $25.1^{\circ} \mathrm{C}$ e $28.0^{\circ} \mathrm{C}$ no período de verão (novembro-abril) e mínimas entre $11.7^{\circ} \mathrm{C}$ e $12.8^{\circ} \mathrm{C}$ no período de inverno (junho-agosto); com temperatura média das máximas anual de $24.9^{\circ} \mathrm{C}$ e a média das mínimas anual de $17.7^{\circ} \mathrm{C}$.

Esta pesquisa foi realizada no Parque Trianon na cidade de São Paulo/SP (Figuras 1 e 2), localizado no espigão da Avenida Paulista no bairro Bela Vista, um dos parques 'ancora' de infraestrutura verde do Projeto intitulado "Infraestrutura verde para a resiliência urbana às mudanças climáticas da cidade de São Paulo" (Projeto FAPESP N²015/10597-0), cuja área de estudo abrange quatro parques, o parque da Cantareira, o parque da Água Branca, o parque Trianon e o parque do Ibirapuera (Figura 3). 


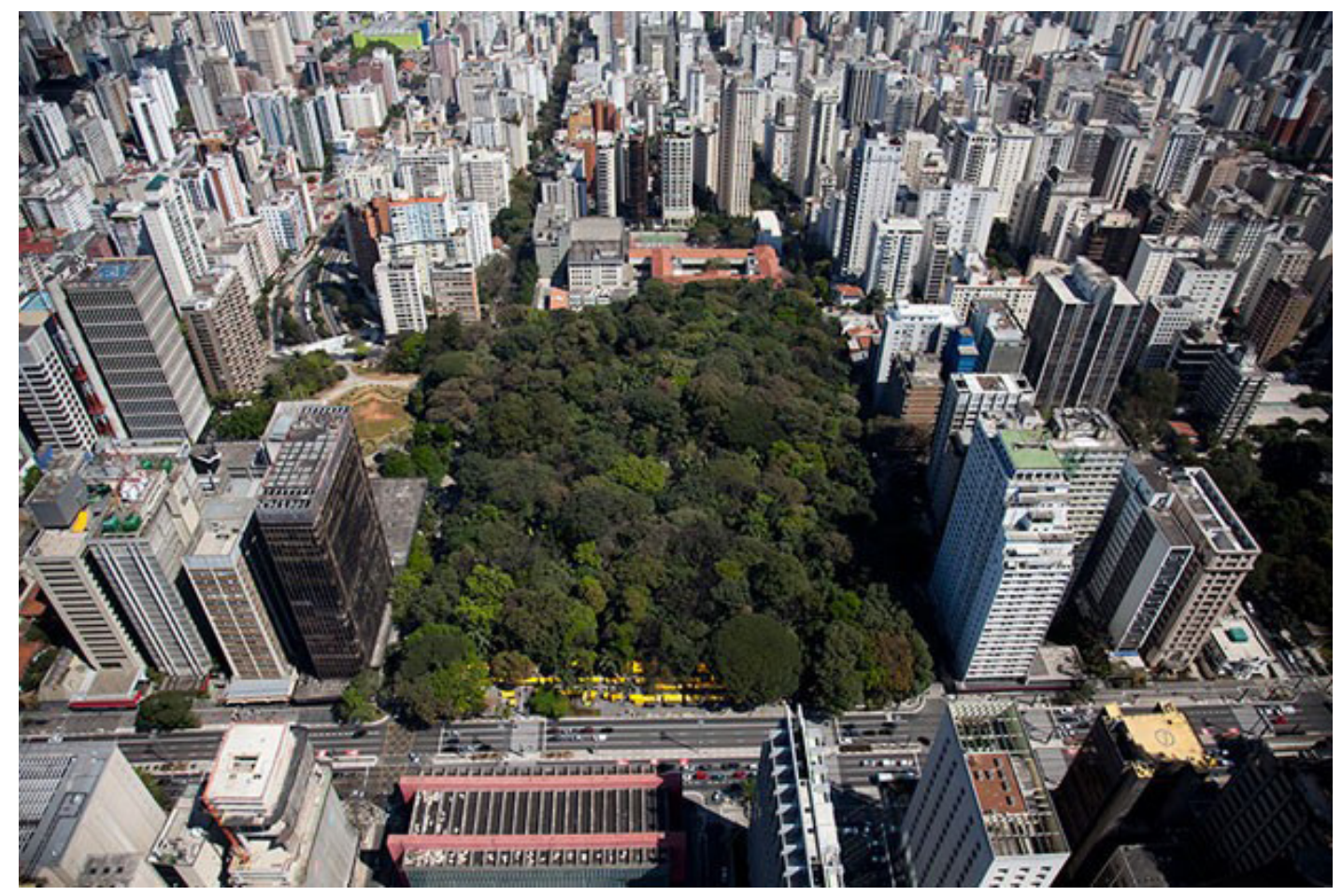

Figura 1 - Parque Trianon - São Paulo/SP. Fonte: Google

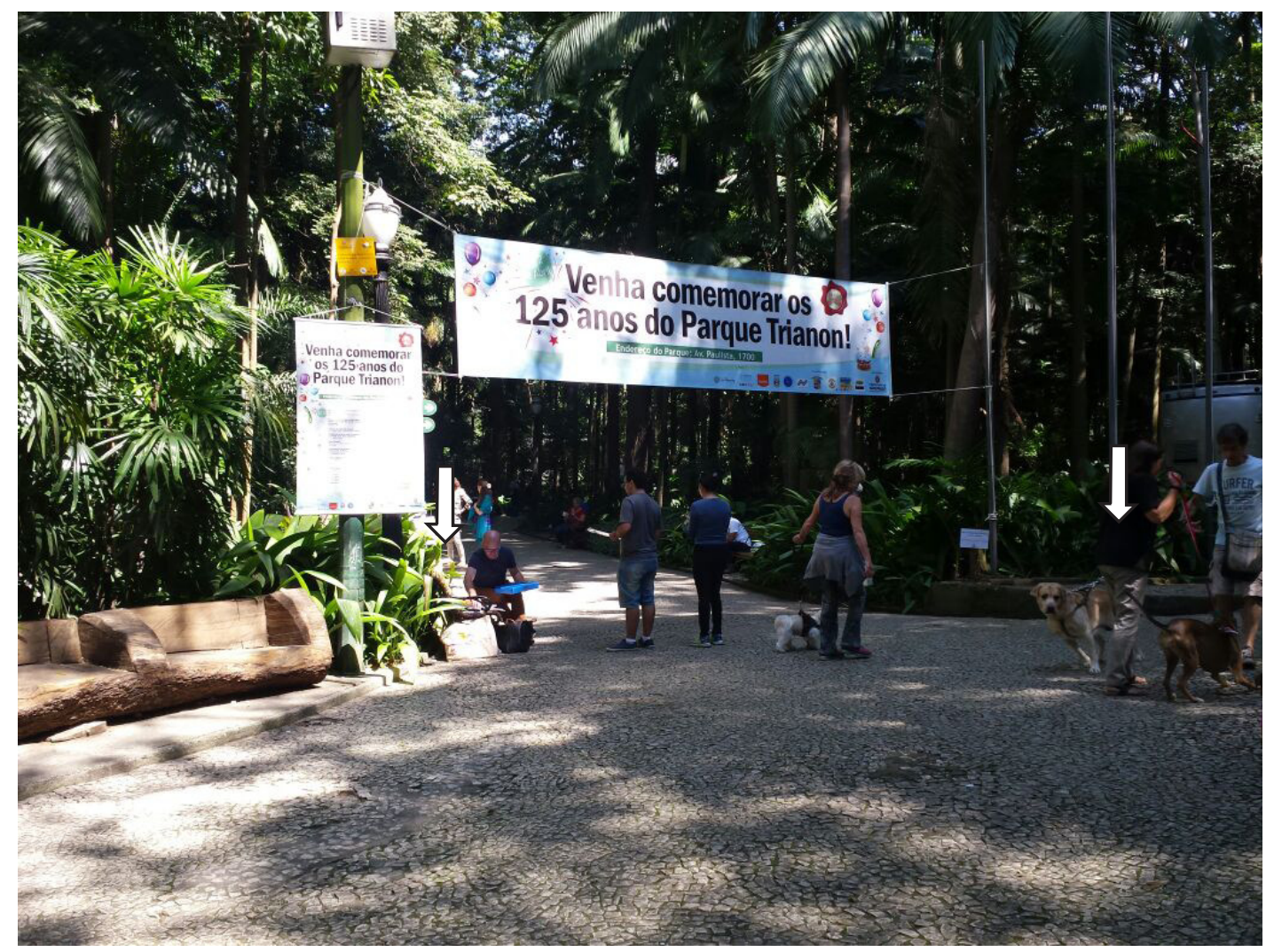

Figura 2 - Parque Trianon - São Paulo/SP - a seta branca indica os pontos onde foram coletados os dados climáticos. Fonte: Aline Silva Santos 


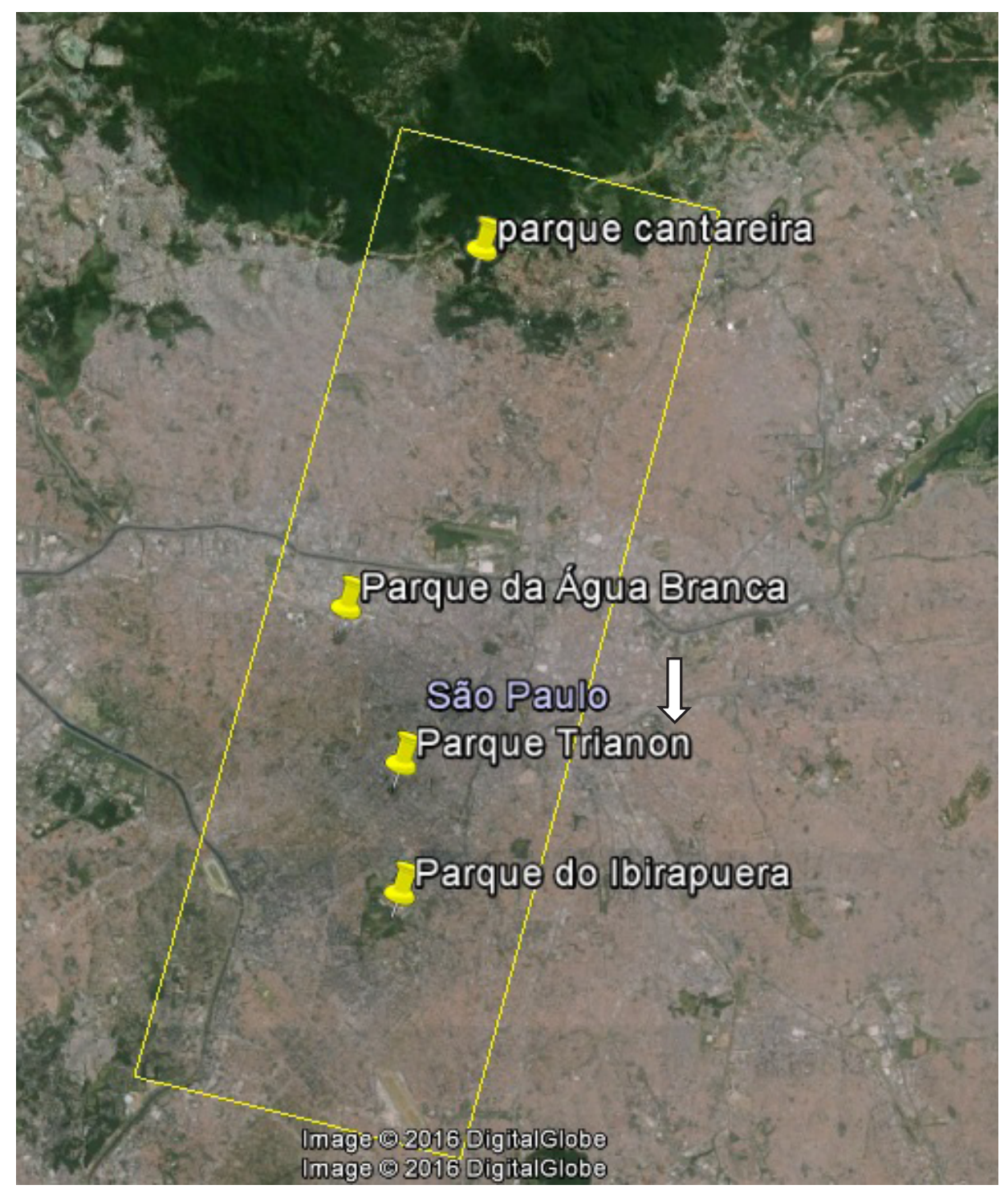

Figura 3 - Área de estudo do Projeto FAPESP N²015/10597-0. Fonte: Google

\subsection{MEDIÇÕES DAS VARIÁVEIS CLIMÁTICAS}

Variáveis climáticas foram aferidas por meio de duas estações meteorológicas portáteis posicionadas em dois pontos, sendo um ao sol e outro a sombra. Devido a grande quantidade de elementos arbóreos, em alguns momentos do dia os dois pontos permaneceram na sombra.

Foram monitoradas a temperatura do ar $\left({ }^{\circ} \mathrm{C}\right)$, temperatura de globo $\left({ }^{\circ} \mathrm{C}\right)$, umidade relativa do ar (\%) e velocidade do vento $(\mathrm{m} / \mathrm{s})$ por meio de equipamentos fixados a um 
tripé a 1,50 $\mathrm{m}$ de altura. Os tripés foram compostos por um registrador de temperatura e umidade relativa do ar, modelo Testo 175 , protegido da radiação; um sensor de temperatura, modelo Testo 175-T2; outro sensor de temperatura, modelo Testo 0613 1711 adaptado ao globo, e um anemômetro/termômetro digital Testo 445 com sensor 0635-1549, protegido por uma caixa de isopor (Figura 4). Todas as medidas foram feitas de 15 em 15 minutos durante o dia 3 de abril de 2017 das $9 \mathrm{~h}$ às $17 \mathrm{~h}$. $O$ tempo manteve-se estável, sem chuva, durante o dia de medição

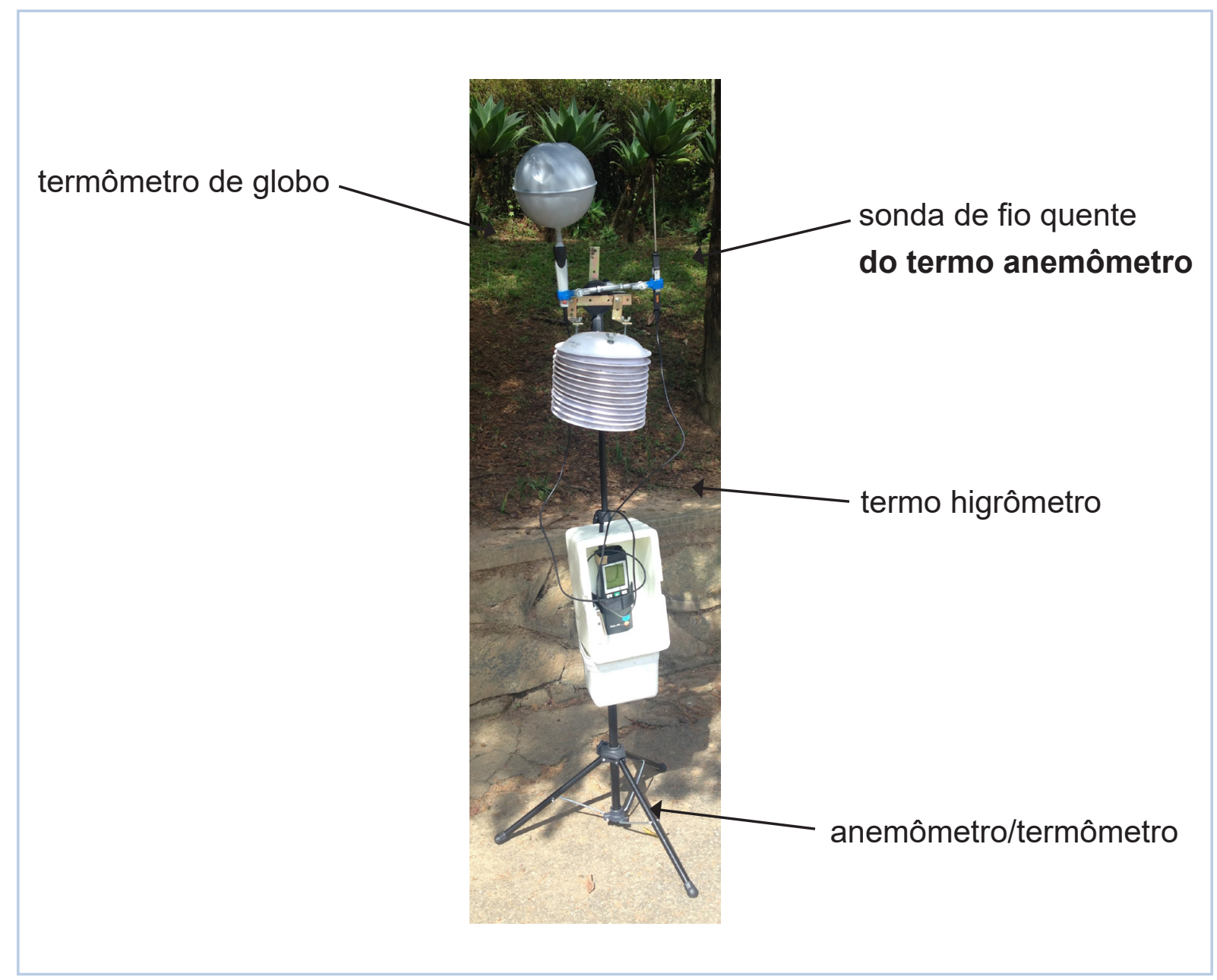

Figura 4 - Estação meteorológica portátil

\subsection{CLASSIFICAÇÃO SUPERVISIONADA}

A classificação supervisionada faz uso de algoritmos para determinar pixels, que representam valores de reflexão característicos para uma determinada classe. É o método mais utilizado na análise quantitativa de dados de sensoriamento remoto. O pro- 
grama MultiSpec® 3.3 é utilizado para a classificação supervisionada, e opera a partir da seleção de campos de treinamento e de testes para classes específicas de áreas conhecidas. Nesse programa, o operador estabelece diferentes tipos de classe de acordo com as áreas de interesse, utilizando para isso imagens de satélite, que permitem elaborar classificações supervisionadas do mosaico e das imagens dos locais em análise. Foi feita a classificação supervisionada da área do parque Trianon, assim como um buffer de raio de $1 \mathrm{~km}$ ao redor do parque, a fim de quantificar a cobertura arbórea da área de estudo. Na Figura 5 pode-se observar a quantidade de área vegetada no parque e seu entorno.

\section{RESULTADOS E DISCUSSÂO}

\subsection{CLASSIFICAÇÃO SUPERVISIONADA}

Os resultados da classificação supervisionada (Figura 5) apresentaram um total de $14 \%$ de cobertura arbórea na área em análise. A quantidade de asfalto somada à quantidade de área edificada ficou na ordem de 40\%. Estes resultados apontam uma grande impermeabilização do solo, fato que pode interferir nas condições de conforto térmico no local.

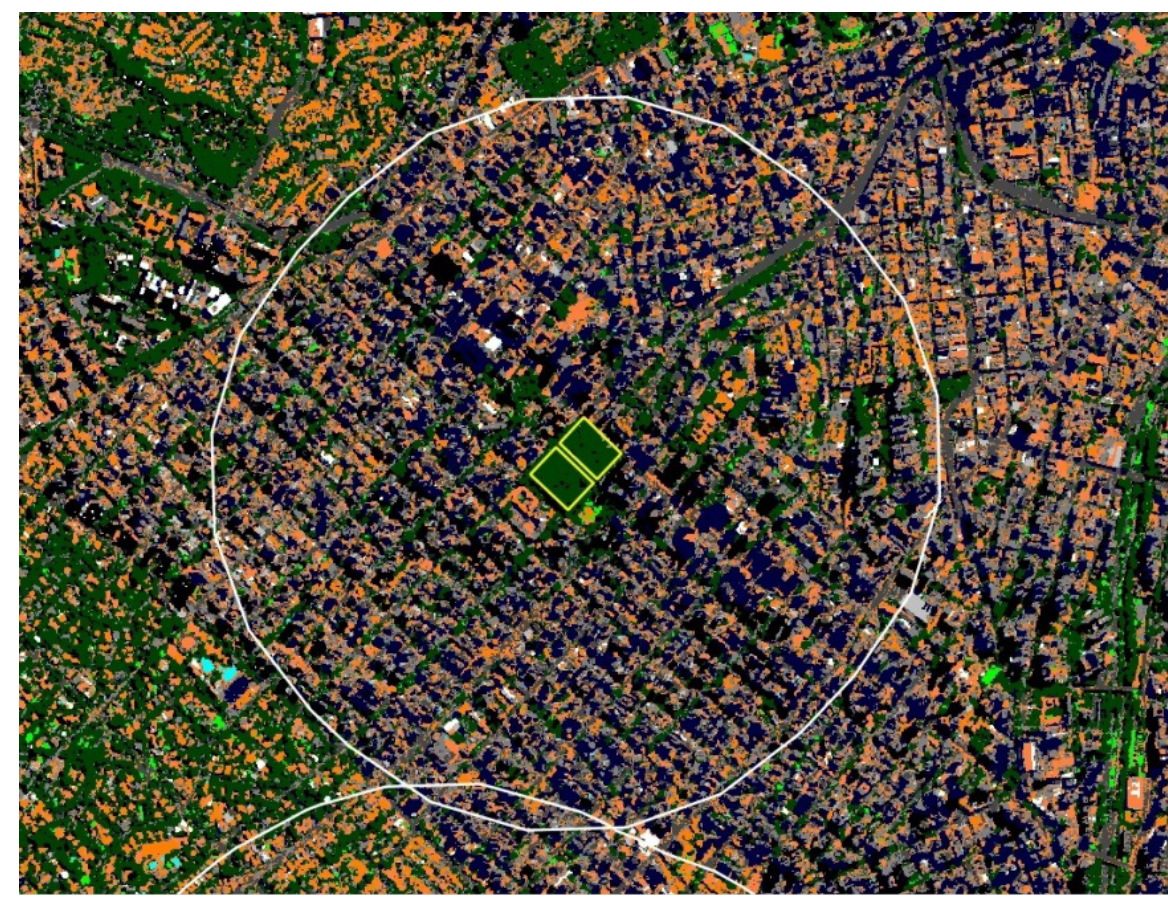

Figura 5 - Classificação Supervisionada do Parque Trianon e seu entorno

\section{Legenda}

Parque Trianon

Cobertura arbórea $(14,2 \%)$ Relvado $(0,4 \%)$ Solo exposto $(6,7 \%)$ Asfalto (12,4\%) Sombra $(12,6 \%)$ Rio/Lago (25,2\%) Pisana (0,3\%) Telha clara $(0,6 \%)$ Telha esara (16,8\%) Telha cinza $(1,5 \%)$ Telha cerâmica $(9,3 \%)$ 


\subsection{VARIÁVEIS CLIMÁTICAS}

As variáveis microclimáticas: umidade relativa do ar (\%) e temperatura do $\operatorname{ar}\left({ }^{\circ} \mathrm{C}\right)$ obtidas na área de estudos, ao sol e à sombra, não apresentaram diferenças significativas na umidade relativa e temperatura do ar. A velocidade do vento $(\mathrm{m} / \mathrm{s})$ máxima medida foi $1,40 \mathrm{~m} / \mathrm{s}$ e mínima de $0,00 \mathrm{~m} / \mathrm{s}$ (Figura 6 ).

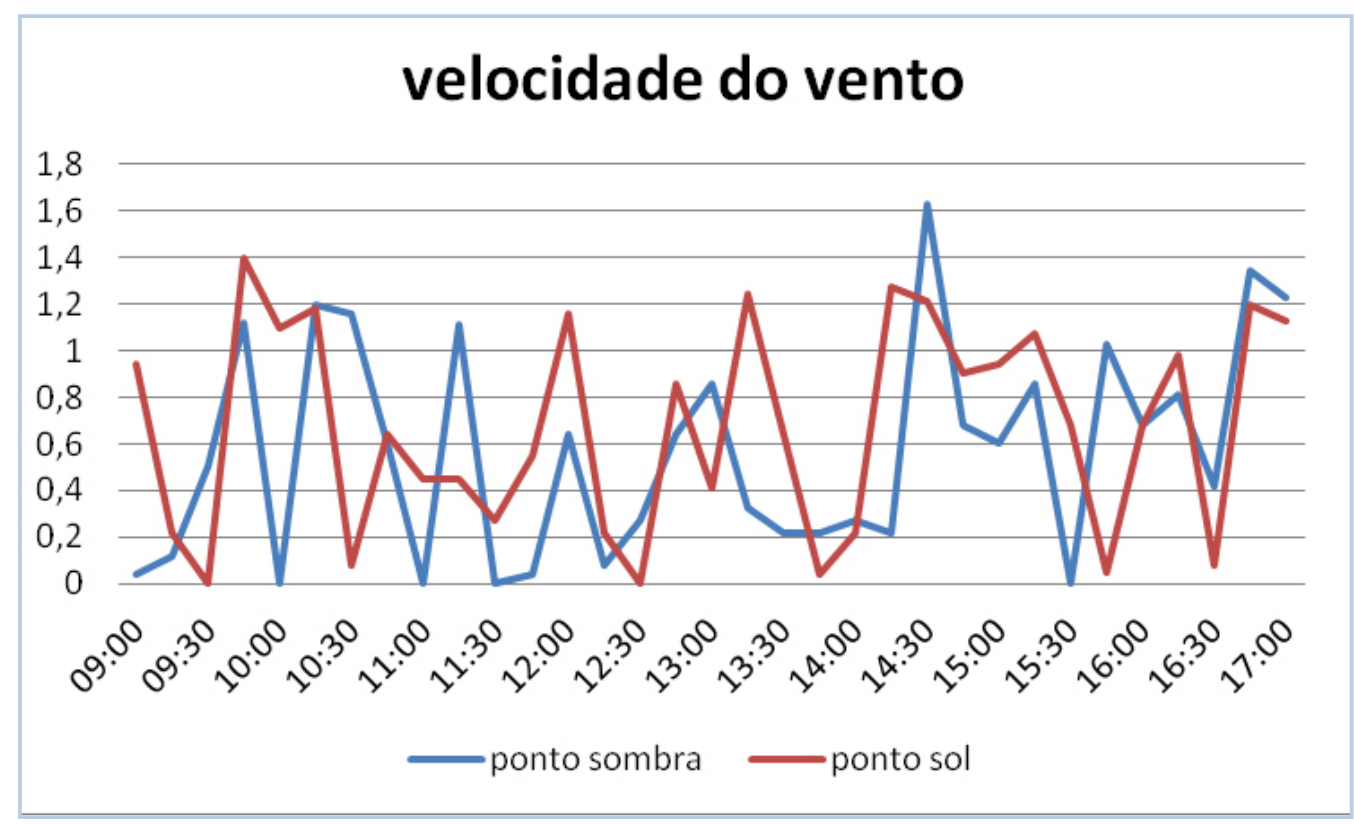

Figura 6 - Velocidades do vento aferidas nos pontos (sol e sombra)

A média da temperatura do ar ao sol foi de $23,34^{\circ} \mathrm{C}$ e à sombra de $23,12^{\circ} \mathrm{C}$. A média da umidade relativa do ar ao sol foi de $62,92 \%$ e à sombra de $64,30 \%$, apresentando poucas alterações como pode ser observado na tabela 1.

A grande quantidade de maciços arbóreos no parque Trianon faz com que o microclima seja bastante homogêneo em toda a sua extensão, não havendo grandes variações entre os dados coletados nos dois pontos. 
Tabela 1 - Média dos dados climáticos aferidos em dois pontos no parque Trianon

\begin{tabular}{|l|l|l|l|l|}
\hline \multirow{2}{*}{ hora } & \multicolumn{2}{|l|}{ temperatura ambiente } & \multicolumn{2}{l|}{ Umidade relativa } \\
\hline & sol & sombra & sol & sombra \\
\hline $9: 00$ & 21,8 & 21,93 & 70,4 & 68,48 \\
\hline $10: 00$ & 21,33 & 21,28 & 66,75 & 68,43 \\
\hline $11: 00$ & 23,23 & 23,03 & 60,15 & 61,4 \\
\hline $12: 00$ & 24,3 & 23,43 & 55,7 & 58,93 \\
\hline $13: 00$ & 24,53 & 24,3 & 51,15 & 52,58 \\
\hline $14: 00$ & 24,83 & 24,65 & 56,3 & 58,25 \\
\hline $15: 00$ & 23,75 & 23,57 & 66,4 & 68,05 \\
\hline $16: 00$ & 23,28 & 23,03 & 69,45 & 71,35 \\
\hline $17: 00$ & 23 & 22,9 & 70 & 71,2 \\
\hline médias & 23,34 & $\mathbf{2 3 , 1 2}$ & $\mathbf{6 2 , 9 2}$ & $\mathbf{6 4 , 3 0}$ \\
\hline
\end{tabular}

O ambiente do parque apresenta-se bastante sombreado pelas árvores, impossibilitando posicionar uma das estações em local que permanecesse o tempo todo ao sol. Nas Figuras 7 e 8 observa-se pouca diferença entre os pontos medidos ao sol e à sombra, tanto para a temperatura como para a umidade relativa do ar.

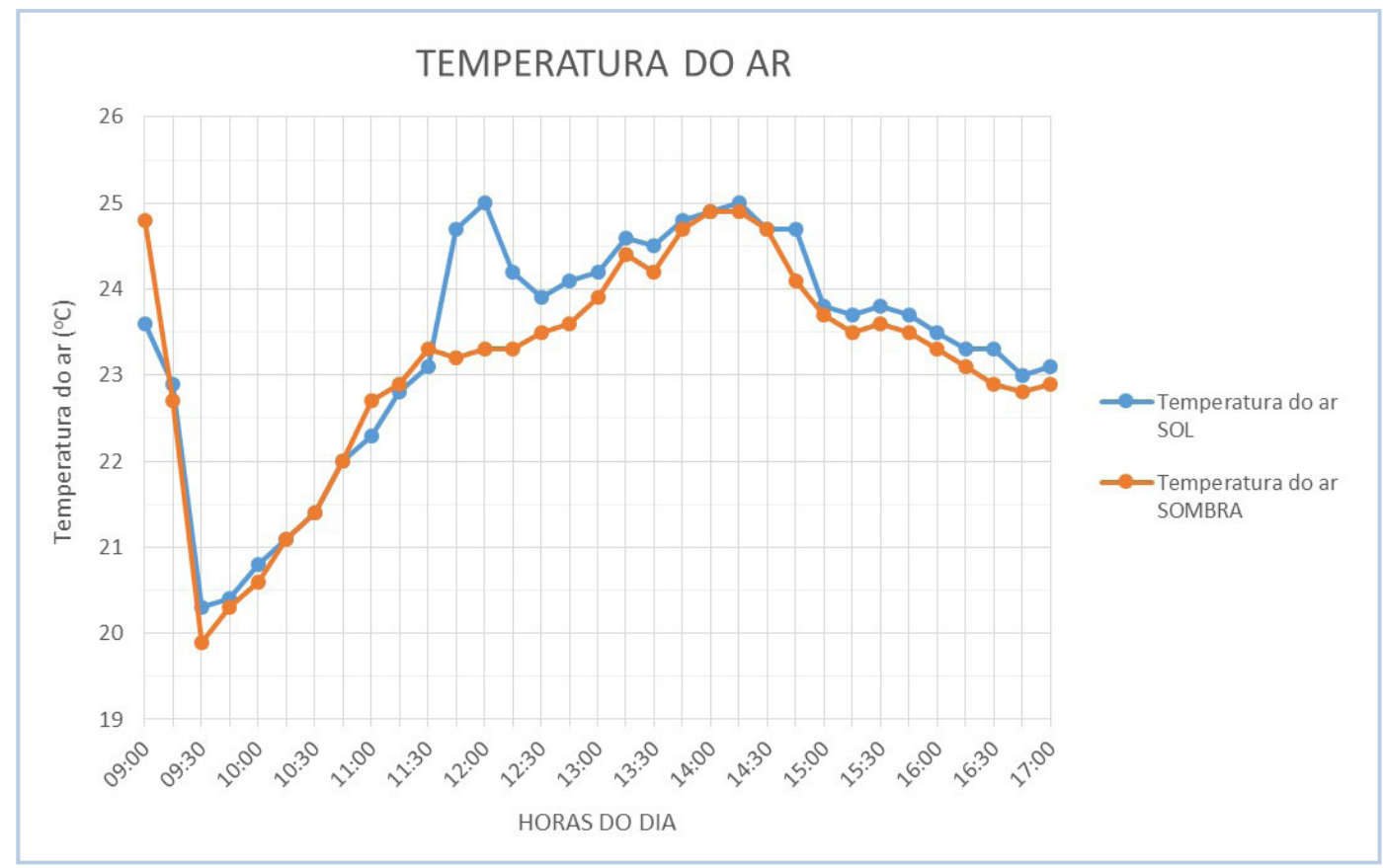

Figura 7 - Comparação da Temperatura do ar nos dois pontos de coleta de dados climáticos no Parque Trianon no dia 03 de abril de 2017 


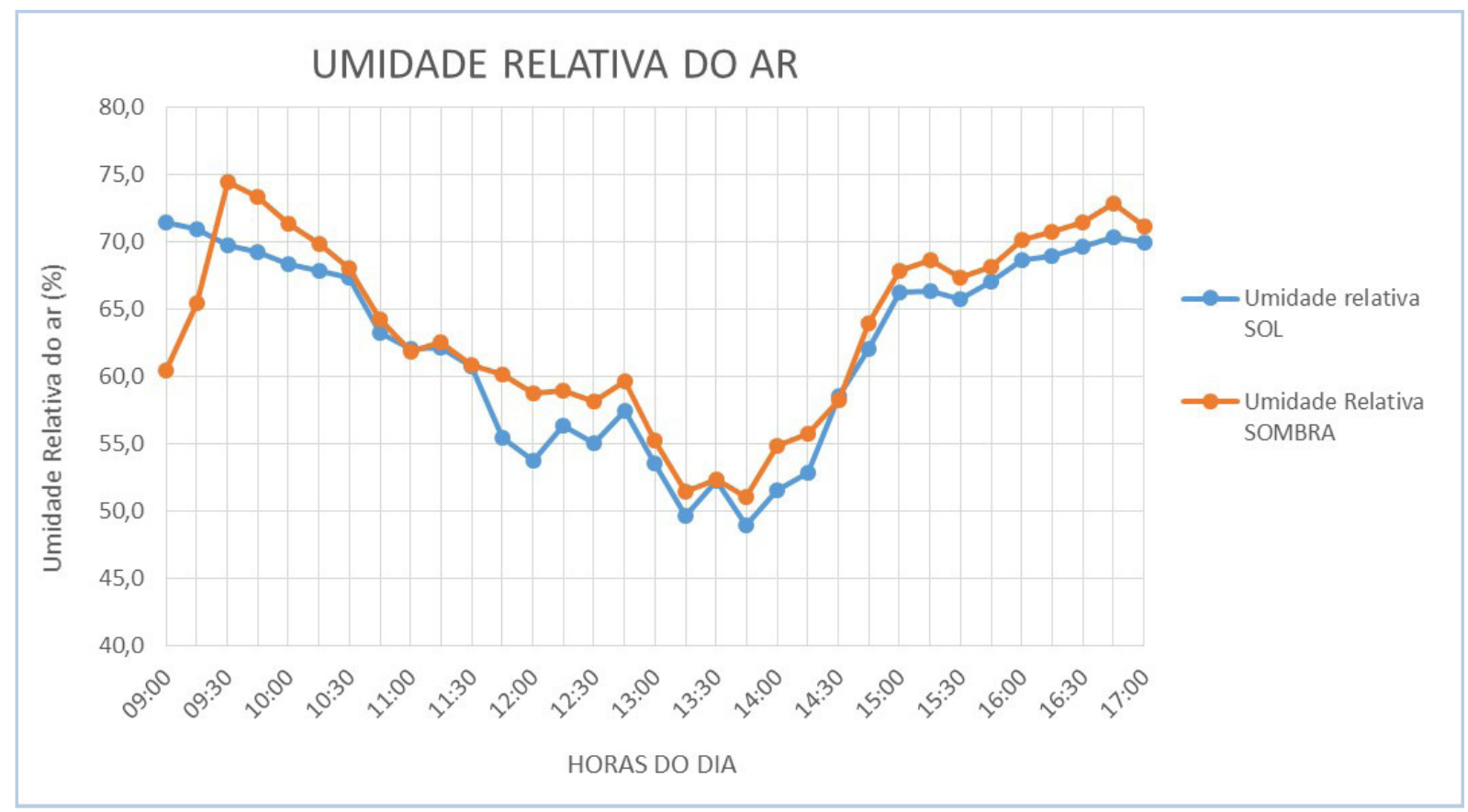

Figura 8 - Comparação da Umidade relativa do ar nos dois pontos de coleta de dados climáticos no Parque Trianon no dia 03 de abril de 2017

Apesar de se tratar de meses com grande ocorrência de chuva, o dia em que foi feita a coleta de dados, assim como o dia anterior, permaneceram estáveis e sem chuva.

\subsection{PERCEPÇÃO DOS USUÁRIOS}

Para verificação da percepção dos usuários no local analisado, questionários foram aplicados a 50 indivíduos com idade mínima de quinze anos, sendo 21 do gênero feminino e 29 do gênero masculino. Foram abordados fatores que interferem nas sensações e percepções relacionadas ao local com o intuito de mapear as condições de conforto e satisfação em relação ao ambiente vivenciado.

Os entrevistados quando inquiridos sobre os motivos pelo qual frequentam o Trianon relataram diversos fatores, dentre eles os que mais ocorreram foram: a busca pelo contato com a natureza a fim de relaxar e reduzir o stress (44\%), atividade física em busca de vida mais saudável $(6 \%)$, o lazer (32\%), o conforto térmico do local $(10 \%)$ e o fator social, o encontro com pessoas e amigos (8\%).

A localização do parque Trianon em local de alta concentração de escritórios e ins- 
tituições comerciais e culturais aumenta a quantidade de usuários no local. Os motivos relatados pelos entrevistados em relação à frequência evidencia sua função restauradora na medida em que é procurado por pessoas que buscam momentos de tranquilidade e calma, corroborando com estudos de Kaplan que comprovam sua Teoria de Restauração da Atenção (KAPPLAN,1995). Ao contrário do que se imagina, o Trianon não assume o papel de parque meramente como via de passagem, mas sim um local agradável de convívio e lazer, como pode ser constatado pelos dados obtidos nas entrevistas.

Com relação à sensação térmica do usuário, $66 \%$ dos entrevistados afirmaram estarem confortáveis, $16 \%$ com pouco calor, $10 \%$ com calor e apenas $8 \%$ com pouco frio. $\mathrm{Na}$ sequência foi questionada a preferência térmica, ou seja, como os entrevistados preferiam que estivesse o clima. As repostas foram: $62 \%$ estavam satisfeitos com a condição térmica do parque, $2 \%$ preferia que estivesse mais calor, $14 \%$ um pouco mais frio, $6 \%$ mais frio, $6 \%$ muito mais frio e $10 \%$ um pouco mais calor.

O dia em que foi feita a pesquisa apresentou temperatura de $29^{\circ} \mathrm{C}$ (máxima) e $22,80^{\circ} \mathrm{C}$ (mínima), fator que influenciou na sensação térmica dos entrevistados. Os usuários mostraram-se muito satisfeitos com a estrutura e espaço físico do parque e com fatores relacionados à segurança, ao ruído e ao conforto térmico como pode ser observado na tabela 2 . Os entrevistados pontuaram cada aspecto baseados em uma escala de 1 a 10 , sendo 1 (nada satisfeito) e 10 (muito satisfeito).

Tabela 2 - Grau de satisfação do usuário em relação ao parque Trianon

\begin{tabular}{|l|l|l|l|l|l|l|l|l|l|l|}
\hline $\begin{array}{l}\text { Grau de } \\
\text { satisfação }\end{array}$ & 1 & 2 & 3 & 4 & 5 & 6 & 7 & 8 & 9 & 10 \\
\hline Estrutura & - & - & - & - & - & - & $10 \%$ & $20 \%$ & $24 \%$ & $46 \%$ \\
\hline Ruído & $4 \%$ & $8 \%$ & $8 \%$ & $2 \%$ & $20 \%$ & $6 \%$ & $6 \%$ & $16 \%$ & $6 \%$ & $24 \%$ \\
\hline Temperatura & - & $2 \%$ & - & - & $2 \%$ & $2 \%$ & - & - & $8 \%$ & $64 \%$ \\
\hline Segurança & - & $4 \%$ & $2 \%$ & $6 \%$ & $14 \%$ & $6 \%$ & $22 \%$ & $14 \%$ & $10 \%$ & $24 \%$ \\
\hline
\end{tabular}


Muitos dos entrevistados se encontravam no parque em razão de estarem próximo ao local de trabalho. A condição de stress também foi avaliada por meio de uma escala de 1 a 10 sendo o valor 1 sem stress e 10 com muito stress (Tabela 3 ).

Tabela 3 - Nível de stress relatado pelos entrevistados.

\begin{tabular}{|l|l|l|l|l|l|l|l|l|l|}
\hline 1 & 2 & 3 & 4 & 5 & 6 & 7 & 8 & 9 & 10 \\
\hline $68 \%$ & $8 \%$ & $6 \%$ & $2 \%$ & $6 \%$ & - & - & $10 \%$ & - & - \\
\hline
\end{tabular}

Os resultados demonstram que a maioria (68\%) dos usuários do parque não estava estressada ou com leve grau de stress e apenas $10 \%$ da população entrevistada apresentou níveis de stress mais elevado. O contato com o ambiente natural, segundo os entrevistados auxilia na recuperação da fadiga do dia a dia.

\section{CONCLUSÕES}

Os resultados deste estudo apontaram a importância de parques urbanos nas cidades, na medida em que proporcionam bem-estar aos seus usuários, enfatizando a importância de ambientes naturais no meio urbano.

Os motivos relatados pelos entrevistados por frequentarem o parque evidenciou sua função restauradora das áreas verdes na medida em que é procurado por pessoas que buscam momentos de tranquilidade e calma, auxiliando assim na recuperação da fadiga mental.

Em relação ao microclima, faz-se necessário um monitoramento das variáveis climáticas por um período mais longo de tempo e em diferentes épocas do ano, nas áreas de estudo, assim como em seu entorno.

Assim sendo, destaca-se a importância da realização de mais pesquisas para que se possa comprovar os efeitos provocados pela inserção de árvores nos parques urbanos, não só relacionados ao conforto térmico mas também ao bem estar dos habitantes das cidades, tendo em vista a valorização da infraestrutura verde como elemento importante para resiliência urbana, visando um melhor desempenho ambiental das cidades. 


\section{REFERÊNCIAS BIBLIOGRÁFICAS}

CHENG, V.; NG, E.; CHAN, C.; GIVONI, B. An experiment of urban human thermal comfort in hot and humid sub-tropical city of Hong Kong under high density urban morphological conditions, Hong Kong. In: JAPANESE-GERMAN MEETING ON URBAN CLIMATOLOGY, 2009.Freiburg. Proceedings... Freiburg, 2009.p.179-184

COHEN, P.; POTCHTER, O.; MATZARAKIS, A. Daily and seasonal climatic conditions of green urban open spaces in the Mediterranean climate and their impact on human comfort, Building and Environment V.51, 2012, p. 285-295

DACANAL, C.; LABAKI, L. C. Vamos passear na floresta! O conforto térmico em fragmentos florestais urbanos, Ambiente Construído, Porto Alegre, v. 10, p.115-132, 2010

DIMOUDI, A.; NIKOLOPOULOU M. Vegetation in the urban environment: microclimatic analysis and benefits. Energy Building, v.35, p.69-76, 2003

DOBBERT, L. Y.; PRATA-SHIMOMURA, A. R.; MENDES, F. H.; SILVA FILHO, D. F. The influence of tree canopy cover on urban thermal comfort, Pluris - reinventar a cidade em tempos de mudança, $6^{\circ}$ congresso luso-brasileiro para planeamento urbano, regional, integrado e sustentável, Fundação Calouste Gulbenkian, Lisboa, p.1509-1516,2014.

HARTIG, T.; MITCHELL, R.; DE VRIES, S.; FRUMKIN, H. Nature and health. Annu Rev Public Health, V.35, P. 207-228, 2014.

KÁNTOR, N.; UNGER, J. The most problematic variable in the course of humanbiometeorological comfort assessment - the mean radiant temperature, Central European, Journal of Geosciences v.3, p.90-100, 2011.

KAPLAN, S.; KAPLAN, R. Cognition and environments, functioning in an uncertain world. Ann Arbor: University of Michigan; Ed. Ulrich’s Books, 287 p., 1983.

KAPLAN, S. The Restorative Benefits of Nature: Toward an Integrative Framework. Journal of Environmental Psychology, v. 15, p.169-182, 1995.

MC PHERSON, E. G.; SIMPSON, J. R.; XIAO, Q.; WU, C. Million trees Los Angeles canopy cover and benefit assessment. Landscape and Urban Planning, Amsterdam, v. 99, p. 40-50. 2011. 
NORTON, B. A.; COUTTS, A. M.; LIVESLEV, S. J.; HARRIS, R. J.; HUNTER, A. M.; WILLIAMS, N. S. G. Planning for cooler cities: A framework to prioritise green infrastructure to mitigate high temperatures in urban landscapes. Landscape and Urban Planning, v.134, p. 127-138, 2015.

OLIVEIRA, L. A.; MASCARÓ, J. J. Análise da qualidade de vida urbana sob a ótica dos espaços públicos de lazer. Ambiente Construído, v. 7, n. 2, 2007, p. 59 - 69.

SENANAYAKE, I. et al. Remote sensing based analysis of urban heat islands with vegetation cover in Colombo city, Sri Lanka using Landsat-7 ETM+ data. Urban Climate 5, p. 19-35, 2013.

SHASHUA-BAR, L.; TSIROS, I. X.; HOFFMAN, M. E.. A modeling study for evaluating passive cooling scenarios in urban streets with trees. Case study: Athens, Greece, Building and Environment , 45, p.2798-2807, 2010.

SHASHUA-BAR, L.; PEARLMUTTER, D.; ERELL, E. The influence of trees and grass on outdoor thermal comfort in a hot-arid environment. International Journal of Climatology, Chichester, v. 31, p. 498-506. 2011.

SPANGENBERG, J., SHINZATO, P., JOHANSSON, E., DUARTE, D. Simulation of the influence of vegetation on microclimate and thermal comfort in the city of São Paulo, Revsbau, V.3, n.2, p. 1-19, 2008.

ULRICH, R. S. Natural versus urban scenes: some psychophysiological effects. Environment \& Behavior, Ann Arbor, v. 13, n. 5, p. 523-556, 1981.

ULRICH, R. S. Health Benefits of Gardens in Hospitals. Paper for conference, Plants for People, International Exhibition Floriade, 2002, 10p. 